\title{
Reculturing Pedagogical Practice: Probing Teachers' Cultural Models of Pedagogy
}

\author{
Essaid Chafi (Corresponding author) \\ Laboratory IDDS, University Hassan I, FST, Settat, Morocco \\ E-mail: myessaidchafi@gmail.com \\ Elmostapha Elkhouzai \\ Laboratory IDDS, University Hassan I, FST, Settat, Morocco \\ E-mail: elkhouzai_m@yahoo.fr
}

Received: 05-01-2017

doi:10.7575/aiac.ijels.v.5n. 1 p. 78
Accepted: 23-01-2017

Published: 31-01-2017

\begin{abstract}
A number of educational reform attempts, chief among which are pedagogy by objectives, competency-based approach, and pedagogy of integration, have been made to establish pedagogical reform in Moroccan public primary school. However, results have not been up to par. Failure of school reform has been largely rationalized in terms of technical problems associated with innovation delivery system. By adopting a "technicist" stance towards issues of pedagogical reform, decision makers and curriculum developers have paid a scant attention to the fact that pedagogical innovations are social constructions, and as such value-laden. The institutionalization of pedagogical frameworks import has so far failed to take into account the local sociocultural meanings. A close look into our classrooms shapes an understanding why prevailing traditional practices persist in spite of the progressive ideals advocated in reform packages. Pedagogy is more than techniques; it is deeply embedded in the sociocultural context. Upgrading pedagogical practice requires a sociocultural approach in which the nature of the cultural perspective of pedagogy is recognized and failure of pedagogical reform is also sought in the workings of the enveloping social structure. Such a cultural undertaking of pedagogy can be fulfilled by probing teachers' cultural models of pedagogy. Without proper examination and understanding of teachers' conceptualization of pedagogy and how it reflects on classroom practice, it will be difficult to determine an appropriate focus for pedagogical reform. Therefore, the study of teachers' cultural models of pedagogy has the potential to provide reflective insight into many facets of teachers' thinking and practice. Attentiveness to cultural models of pedagogy can lead and enlighten educational practice towards directions that current research has not explored yet.
\end{abstract}

Keywords: Teacher, culture, pedagogy, reform, cultural models

\section{Introduction}

Following the economic hardship of the 1990's, Moroccan stakeholders stressed the pressing need to reform the educational system to stimulate its economic recovery and to keep abreast of rapid social, political and economic challenges transpiring as a consequence of globalization (Chafi, Elkhouzai \& Ouchouid 2016). This culminated in a movement toward educational reform represented in the National Charter for Education and Training (1999) and decentralization as parts of a strategic plan to economic recovery. In 2000, the Ministry of Education adopted the Charter's project and declared 2000-2009 the National Decade for Education and Training with a conviction that the development of manpower and its rehabilitation is a type of investment in a nation's resources (Chafi et al., 2016).

Pressed by the exigency to raise the quality of Moroccan education, the Charter prioritized the interests of elementary school pupils and placed them at the core of the educational undertaking. The reform was put in place to effectuate a "paradigm shift from traditional, knowledge-based transmission style of teaching to a more student-centered, experience-based, problem solving approach of teaching" (Chafi et al., 2016). There was insistence on reflection and active learning to extend learners' cognitive and metacognitive strategies, and boost their cooperative and interactive abilities. The Pedagogical Guideline for Primary School reflects this tendency: "the reform of education and training system situate the learner in general and children in particular at the heart of attention, thinking and acting in the process of education and training" (Ministry of National Education and Vocational Training, 2009, p. 17). This endeavor is projected to be accomplished by way of espousing "an active educational approach that goes beyond passive reception and individual work to the espousal of self-learning and the ability to dialogue and participate in collective endeavors" (Ministry of National Education and Vocational Training, 2009, p. 17). The theoretical reference framing the curriculum reflects the adopted competency-based approach, which lays emphasis on the urgency to 
prepare students to respond to the prerequisites of globalization and technological progress (Ministry of National Education and Vocational Training, 2009, p. 22).

Following years of implementation, however, the adopted learner-centered approach has been ineffective in respect of being institutionalized and does not seem to have fulfilled its desideratum. Laudable though the implementation efforts are, the situation in Moroccan public primary classroom still leaves much to be desired. A close look into the pedagogical practices within primary classrooms reveals the chasm existing between policy ideals and extant classroom reality. Teachers still "transmit knowledge to be regurgitated by learners who are expected to passively and unselectively copy and reproduce the conveyed information in its 'original' and 'objective' form. Horizontal information flow and interaction are quasi-absent under the pressure of vertical interaction. Classroom pedagogical practices remain largely geared towards transmitting pre-packaged knowledge" (Chafi et al., 2016). Learner-centered teaching has not yet taken root in Moroccan primary classrooms even though considerable resources have been allocated to attain the end in view.

More often than not, this poor pedagogical performance has been ascribed to technical problems such as poor training programs resulting in inadequate teacher quality, poor governance, scarcity of resources, and large class sizes. The ways teachers conceptualize pedagogy and the effect that the enveloping cultural environment might have on classroom practices have not been given due consideration. Even though the Charter (1999) declares to have as its encompassing objective to embrace a new approach to education that should be forward-looking with a deep-seated Moroccan identity, a thorough and meticulous perusal of the clauses of the Charter and the more recent Emergency Plan (2009) discloses no apparent concern for the Moroccan identity and by extension for prevailing cultural values and, more specifically for, pedagogical practices from a cultural perspective. The cultural aspect of pedagogical reform has not yet received due attention. It is out of this concern that we call for a systematic examination of teachers' cultural models of pedagogy that lend a motivational force to classroom pedagogical practices. These models may hamper the implementation of reform ideals and induction of pedagogical change in primary school practices if they remain outside the educational limelight.

The marginalization of context has only paved the ground to endorse a "technicist" (Elliot, 1994) approach to teaching and learning, leading to the rendering of teaching and learning as context-free, non-problematic activities. Cultural inattentiveness in the treatment of teaching and learning has propagated the view that these are generic activities. The philosophical basis of this technicist frame of reference on teaching and learning can be traced back to the application of scientific rationality (positivism) to teaching. Given the claims of scientific knowledge to universality, models of teaching and learning derived from this form of knowledge have likewise laid claim to universal applicability, leading to the dominant (albeit implicit) view that teaching and learning are value-free activities. Reality is independent of social and cultural construction and can be controlled and manipulated. Undoubtedly, the technicist stance, marginalizing context, considering teaching and learning as value-free activities, and viewing reality as independent of social and cultural constructions to problems of pedagogical renewal has deflected attention away from the influence of the wider cultural dimensions related to teaching and learning that markedly impact on the locus of change. In default of thoughtful consideration of local context and how teachers conceptualize pedagogy and pedagogical practices, we will be hardly able to comprehend why efforts to integrate successfully learner-centered pedagogy in classrooms have not yet yielded the anticipated results. So long as pedagogical renewal is perceived as a technical concern, reaction to reform failure will customarily be technical in nature as well. In view of that, unfortunately, the same technical view to pedagogical reform seems to characterize the new perspective on pedagogical reform proposed by The Curriculum Directorate as a part of 2015-2030-Strategic Vision for Moroccan School Reform. The new plan aims at enhancing students' performance in primary school by adopting certain measures such as reducing teacher workload, revisiting textbooks, thinning subject content, emphasizing basic skills: reading, writing and arithmetic, quick-fix workshops to acquaint teachers with new measures expected to be put into effect (Ministry of National Education and Vocational Training, 2015).

\section{The cultural dimension in educational undertakings}

In the context of education, culture is at the heart of all our practices, including curriculum, instructions, interactions, and assessment (Gay, 2010). Culture has an impact on how we think, perceive, act and communicate-all of which influence how we teach and how we learn. The whole educational venture pertains to culture (Erickson, 2002). Classroom culture is the outcome of what teachers and students bring to it with regard to understanding, beliefs, and values, and the way these have an effect on the social interactions within that context. By the same token, Nickson (1994) writes of the "invisible and apparently shared meanings that teachers and pupils bring to ... classroom and that govern their interaction in it" (p. 8). The statement carries certain inferences. First, there is a classroom culture constituted by what instructors and learners bring to the space of classroom - norms, beliefs, assumptions, and expectations as well as what they do in classroom. Moreover, this invisible culture directs the meanings and behaviors developed within it. Characterizing culture in this manner incorporates not only teachers' and learners' worldly experience but also the societal sway that aid in constructing them. Therefore, investigating the role of culture in human life is a prerequisite to our understanding of the educational practice. The latter shapes teaching and learning in significant ways. The concept of classroom culture comprises the beliefs, assumptions, and values that teachers and students abide by and those practices that regulate what is seen as tolerable or intolerable in the classroom. Whether 
educators are aware of it or not, culture is an invisible road map that guides their personal and professional lives. The act of "teaching cultures are embodied in the work-related beliefs and knowledge teachers share-beliefs about appropriate ways of acting on the job and rewarding aspects of teaching, and knowledge that enables teachers to do their work" (Feiman-Nemser \& Floden, 1986, p. 508). Centralizing cultural issues in the study of classroom practices can illuminate the way through which the "invisible" constituents in the teaching and learning process may enhance or impair the nature of the learning that materializes.

Educators recurrently overlook the cultural dimension in educational undertakings (Alexander, 2001). Pedagogical reform efforts are usually preoccupied with technical issues but pay scant attention to the values, beliefs and assumptions that practitioners hold on teaching and learning. Teachers are not culturally void when they step into classrooms; their cultural luggage (beliefs and assumptions - cultural models) impacts on their pedagogical practices. A specific importance needs to be attached to the 'human face' of educational endeavors (Shahan, 1976), which embraces feelings, beliefs, and pedagogical assumptions of teachers. Change might concretize when teachers gain a solid understanding of the cultural foundations that nourish and nurture their classroom behavior. Systems of national education are ingrained in national culture and education is one of the key ways through which culture is communicated and maintained. Shrinking the act teaching to decontextualized measurable behaviors may yield some helpful indicators, but once behavior and culture are so determinedly separated such indicators may have bounded explanatory power (Alexander, 2001). Hence, understanding classroom practices remains shortened without allusion to the local network of thoughts, assumptions, values, and worldviews.

By aiding teachers question their own teaching, they would be in a better position to problematize the taken-for-granted aspect of their work and visualize alternative courses of action that challenge and supplant their ingrained beliefs and practices. Alteration of mindsets may not be realized if teachers are not assisted in exploring these values and assumptions, prompted to reflect on their classroom behavior, and convinced that there is a need for change. Fullan cautions that "Mandates alter some things, but they don't affect what matters. When complex change is involved, people do not and cannot change by being told to do so" (1997, p. 38).

Teachers are not mere implementers of educational renewal entrusted to them by policy makers. Teachers construe, adjust, and put into operation innovations in accordance with their beliefs and contexts (Keys, 2007). Therefore, considering how teachers' cultural models of pedagogy extend influence to classroom pedagogical practice will yield insights and fundamental messages for curriculum developers, policy makers, change agents, and teacher educators. Markee (1997) affirmed that curriculum planners and educational policy makers habitually apply themselves to planning and initiation stages and concerns discounting stumbling blocks and complications that may unfold at some phases in the actual implementation. Commitment to changing school practice entails engagement in cultural change for the reason that superficial change can be a diversion and a way of deflecting attention away from serious development work (Harris, 2002, p. 23). Alteration of beliefs and assumptions are crucial to the change process because they feed classroom practices, and "may be responsible for the perpetuation of antiquated and ineffectual teaching practices" (Pajares, 1992). Therefore, pedagogical practices cannot be changed if practitioners do not change the way they think. Stacey (1996, p. 278) convincingly argues that "People who begin to think differently will almost certainly begin to act differently, and they will then almost certainly affect someone else who will begin to behave differently." Altering the way we think can reflect on the way we act.

Altering classroom practices entails probing pedagogical beliefs, values and norms. In other words, classrooms are in need of "reculturing"-reshaping of values, beliefs and mindsets (Hargreaves, 1997). Pedagogical renewal rests on modifying teachers' classroom behavior, which is motivated by a set of shared assumptions and beliefs (cultural models). The alteration of classroom pedagogical practices entails "fixing people" (Fullan, 1982) because our values and assumptions "put blinders on what we look at, choose to change, and evaluate... Because our values and assumptions are usually implicit and 'second nature,' we proceed as if the way things are is the way things should or could be" (Sarason, 1996, pp. 136-137). We view classroom pedagogy through the lens of our own values and background. As implicitly sustained beliefs, cultural models sway teachers' cognitive processes and, therefore, instructional practices. If our intention is to advance students' attainment and upgrade the quality of classroom performance and engagement, we are required to start by taking account of teachers' cultural models of pedagogy and how they may further or restrain the process of learning.

Goh (1999, p. 18) confirms that "innovators must take steps to ensure that after investing so much time and money in disseminating the innovation, the final and most crucial stage of implementation is not left to chance." This indicates that inquiring into what ensues all through the implementation stage should amount to a fundamental part of any educational innovation. Without profound knowledge of what takes place in the course of the implementation stage, it is inconceivable to scrutinize the latent reasons behind the failure of educational reforms (Fullan, 1982). Echoing Fullan, Schlechty asserts that "Structural change that is not supported by cultural change will eventually be overwhelmed by the culture, for it is in the culture that any organization finds meaning and stability" (1997, p. 136). Accordingly, prioritizing the investigation of teacher thinking and mental representation of pedagogy and pedagogical practices can valuably inform future reform efforts. 


\section{The nexus of culture and pedagogy}

Culture has an influence not only on what is taught but also on how it is taught (Alexander, 2001). Alexander affirms that culture is not superfluous to school environment, nor is it one of a set of variables that might be neatly bundled awaiting cultural analysis. Culture propels and permeates what transpires in classrooms from what is hung on the walls to what goes on inside teachers and pupils' heads. Classroom interaction is framed by routines, rules and rituals that are culturally constituted; teaching and culture come together as pedagogy. Effective teaching arises from refocusing "attention to cultural, psychological, epistemological and situational considerations, not merely organizational and technical considerations" (Alexander, 2001, p. 30). On a related note, Schlechty (1997) cautions that "structural change that is not supported by cultural change will eventually be overwhelmed by the culture, for it is in the culture that any organization finds meaning and stability" (p. 136). Thus, pedagogical reform cannot effectively materialize independently of the cultural environment that frames and constructs it; "Cultural myopia is a particularly weak foundation for educational reform" (Guthrie, 2011, p. 200). Our values and assumptions "put blinders on what we look at, choose to change, and evaluate... Because our values and assumptions are usually implicit and 'second nature,' we proceed as if the way things are is the way things should or could be" (Sarason, 1996, pp. 136-137). We need to understand and analyze our own cultural influences on our classroom practice if we truly aspire to scale up the quality of our classroom performance.

A great deal of research on how to promote classroom practice has been misleading as it has not considered the ways through which local culture shapes and influences implementation processes of innovation in the field of education. Pollard (1985) suggests that cultures are products of people within schools and significantly influence the classroom actions of both teachers and learners. In default of serious consideration of cultural factors, Fuller and Clarke (1994) argue, spending money on large scale projects to improve national education system is of little avail. Understanding the process of change and effectively implementing it go through adopting a cultural perspective as the cultural environment can define teachers' thoughts in the sense that "no sociological environment exist or has identity independent of the way human being seize meaning and resources from it, while every human being's subjectivity and mental life are altered through the process of seizing meanings and resources from cultural environment and using them" (Shweder, 1990, p. 2). In view of that, teachers' thinking or mental life cannot exist independent of the cultural environment that frames and constructs it. Any depiction of pedagogy remains curtailed if the mediation of teachers' thought and action by culture is not taken into account. Therefore, a cultural analysis of teacher thinking can enlighten the way in which culture as a set of constitutive rules constructs teacher thinking and teaching. Using the concept of cultural model, this research attempts to provide such an analysis.

Investigating classroom practices may allow us to unravel tacit assumptions and beliefs that lend a directive force to these practices and amount to manifestations of culture in a way that may assist in sustaining improvement endeavors. Guthrie (2011, p. 200) states that "Teaching is a cultural act, and so is attempting to improve it." In the micro context of classrooms, there is neglect of how teachers understand the world of the classroom and the significance of that in any reform strategy to bring about change and development. We believe that it is the classroom where the crucial decisionmaking occurs. If the crux of school reform is the quality of teaching and learning, then the classroom is where the focus of research needs to be; the classroom is the central place where teaching and learning materialize. School reform literature has not always accentuated the complexity of classrooms and assumed a top down approach, which often underscores the school organizational and structural levels; however, we believe that an awareness of the context of the classroom, the practices of those operating within it, and the values, beliefs and assumptions informing these practices are pivotal in optimizing change.

No noteworthy change may occur in pedagogical practices unless we confront the conceptions that inform and support current practices. The tacit frameworks that underpin teachers' thinking and behavior within the space of the classroom are essential to pedagogical renewal (Day et al., 1993; Pajares, 1992) because they are fashioned by the culture that engulfs teachers. The analysis of primary school teachers' pedagogical thinking and action with reference to their embeddedness in the values and norms of our culture or elsewhere is sporadically dealt with in the literature grappling with pedagogical issues.

Clarke (2003) draws attention to the dearth of literature articulating how the social structures find its way into the heart of the classroom. She maintains that "the location of teacher thinking and teaching in a larger meaning system and the implication of this embeddeness for reform in instruction have received little attention”. Similarly Alexander (2009, p. 932) points out that cultural values overflow at every point in the study of pedagogy, yet "it is one of the abiding weaknesses of much mainstream research on teaching...that it tends to play down their significance in shaping and explaining observable practice". Although research related to teacher-child relationships is prolific, specific research portraying the nature of pedagogical practices as entrenched in the cultural manufacturing of teaching and learning, particularly informed by cultural models, is quasi-absent in the Moroccan context to the best of my knowledge. So, we believe that such a gap needs to be filled through analyzing how Moroccan primary school teachers' cultural models of pedagogy frame their thoughts about pedagogy and subsequently inform their classroom practices. Teachers' mental framework can be conducive or resistive to change. Therefore, it is vital that cultural assumptions and beliefs on pedagogical principles be identified and winnowed. 
Within the framework of cognitive anthropology, cultural models designate intersubjectively shared beliefs by members of a group around diverse subjects, objects, and realms of thought and behavior. These models, being covert and overt in the minds of individuals, afford guidance for and prompt action (Holland \& Quinn, 1987). Cultural models hold a directive power for the individual with reference to the command and persuasiveness anchored in them (D'Andrade, 1995). Accordingly, cultural models

serve as a general basis of guidance, direction, and point of reference for experiencing and acting in the world. As intersubjectively shared conceptions that are culturally and socially constituted, cultural models are anchored in experience and memory, particularly resilient, and deeply ingrained. (Chafi et al., 2016)

In explaining how cultural models operate, Gee (2004) indicates that cultural models are dynamic and adaptable to different contexts, social groups, and situations. Cultural models are acquired not only through experience and memory as but also through shared histories:

People more adept at a domain pass on cultural models through shared stories, practices, and procedures that get newcomers to pay attention to salient features of prototypical cases in the domain - the ones that best reflect the cultural models...cultural models get reinforced and relatively ritualized as they are used in repeated practice. The models and allegiance to the models also become an important bonding cement within the social group associated within a given domain of practice. (p. 45)

Cultural models are passed on to new generations in the course of shared practices and underpinned and ritualized by recurrence and duplication. Observance of the models strengthens intergroup connections. Cultural models can serve to specify what counts as pertinent or impertinent in a given situation. Of similar importance

it should be noted that cultural models are not true or false, may or may not be logical or rationale, may not be realized or conscious, but are very real and instrumental in guiding thought and behavior. When individuals participate in a community, they learn, function within, and become indoctrinated to the cultural models of that community. (Chafi et al., 2016)

When people act in anticipated ways, considering a community's expectations, they carry out a socially-structured identity and react through making use of what they know, deliberately or undeliberately, by dint of an instituted cultural model (Gee, 2004). Individuals and society are mutually constructed and reconstructed during the process of--the employment and construction of--cultural instruments available, the manner by which participants interpret it, the sources of knowledge, and the expertise they employ to work out setbacks they chance upon.

Cultural models are significant both theoretically and practically. Theoretically, cultural models can be perceived within the broader macro-worlds of social institutions; we can utilize cultural models to investigate the multifaceted patterns of institutions and cultures across societies and history (Gee, 2014). Practically, cultural models operate in the local, micro discursive interplays individuals have with each other. Members of the social group share cultural models, which may function as a point of departure for mutual understanding among people. Cultural models can be positioned in connection with situated meaning. Gee sees that situated meaning are understandings that "'hang together' to form a pattern that specific sociocultural groups of people find significant" (1999, p. 41). The discourse valued in and by an institution can be made complex, and cultural models penetrate intricate system of belief and embody the main principles of an institutions in their most straightforward form. Consequently, cultural model link the local micro events and the macro world of institutions. Cultural models are not merely high theory; they are an essential part of our everyday lives as we bring into play our archetypal cultural models to understand our intricate experiences. Subscription to a cultural model does not ensure its utter implementation, given every day practical constraints, competing values and conflicting models (Shore, 1996). With the framework of above conceptualization, exploring

teachers' cultural models of pedagogy serves to illustrate how culture can frame and constitute many aspects of teachers' thinking and practice related to pedagogy. Furthermore, investigating teacher interpretive framework is essential to demonstrate the cognitive process through which meaning is constructed and behavior is influenced and motivated. (Chafi et al., 2016)

The importance of exploring teachers' interpretive structures is anchored in the fact that teachers' preexisting cultural models of pedagogy may deflect attention away from alternate understandings. Policy efforts, with the intention to effect behavioral change by way of educational means, should genuinely reflect on the value of heeding teacher compelling, preexisting cultural models. The institution of new ideas and behaviors that do not reflect teacher interpretive structures is often prevailed over and never entirely taken into account. Novel knowledge is constantly integrated, discarded, and reformed in connection with and interaction with preceding cultural models (Strauss \& Quinn, 1997). When cultural models stabilize over time, they are more likely to frame interpretations of subsequent 
experiences that set them in motion than to be impacted by alternate understandings (Strauss \& Quinn, 1997). As a consequence, whenever fresh experiences or understandings that are "under-schematized" are brought in (i.e., do not entirely connect with existing cultural models), they are likely to activate long-resistant preexisting cultural models with comparable experiential characteristics that give rise to interpretations that substantiate original understandings and forestall new ones from evolving (Strauss \& Quinn, 1997).

Cultural models theory can describe and analyze how primary school teachers understand pedagogy and interact with their learners based on their understanding. We need to examine whether primary school teachers possess or bring into play an organized system of pedagogical knowledge that is informed by cultural models. Cultural models represent latent world representations, mental template constituted by community shared conceptual frameworks used to clarify or coordinate cultural and physical environment constituents (Holland \& Quinn, 1987; Kessing, 1987). Cultural models serve as behavioral operating strategies that correspond to the realization of cultural knowledge on a daily basis, putting in order information and allowing the other to construe sets of outward conditions and decide on the appropriate reply (Holland \& Quinn, 1987). Cultural models are perceived as constructed representations to portray the knowledge espoused, shared, and used by elementary school teachers in their daily experiences and activities. Understanding teachers' cultural models will assist in making sense of and describing how teachers perceive pedagogy and how these perceptions impact on pedagogical practices within classrooms. The purpose is to probe beyond "the observable moves and counter-moves of pedagogy to the values and meanings which these embody" (Alexander, 2001, p. 266). Discerning teachers' cultural models of pedagogy is likely to assist in making sense of and describing how teachers perceive pedagogy and how these perceptions impact on pedagogical practices through investigating culturally based information widely adhered to by public primary school teachers.

The emphasis on exploring teachers' cultural models of pedagogy stems from the fact that teachers are the chief vehicles for the transmission of innovative methods and they are in charge of the realization of curriculum innovation. They are therefore one of the principal factors responsible for the success or failure of curriculum innovation initiatives. Given what we have said above about the junction of culture and pedagogy in a given context, we should expect teachers' beliefs, expectations and attitudes to be of prime importance in any study of pedagogical innovation.

A major benefit of a cultural-models theory is its suitability to demonstrate the cognitive process in the course of which meaning is structured and behavior is prompted. This knowledge may be specifically functional in policy attempts that endeavor to induce conceptual and behavioral change in practitioners for the reason that it assists in elucidating how the cognitive process may restrain or smooth the progress of change. This knowledge, wedded with an identification of practitioners' interpretive cognitive framework (i.e., cultural models), can make available necessary information to augment the efficiency of policy initiatives by highlighting deficient beliefs and internalizing alternative models of good practice.

In conclusion, cultural models are intersubjectively shared world representations that form and structure how individuals in a group comprehend their surrounding and systematize their behavior accordingly. They provide shape, structure and guidance to individual experiences by molding and enlightening perception, cognition, and motivation. They represent culturally originated beliefs, assumptions and practices that are incorporated, enacted, or instituted in day by day life. Cultural models can be thought of as interpretative frameworks. They are both overtly and unconsciously taught and are ingrained in knowledge learned from others as well as from accumulated personal experience. As shared beliefs, cultural models affect teachers' cognitive processes and daily practices. If we seek to advance learners' attainment and commitment, we need to heed teachers' cultural models and how these may assist or restrain the teaching learning process.

\section{Conclusion}

Through adopting a socio-cultural approach to elucidate teachers' conceptualization of pedagogy by virtue of using of cultural models, the teacher is positioned at the core of pedagogical reform. Fullan (2007) reiterates the significance of the teacher in enhancing the quality of education when he affirms that "educational change depends on what teachers do and think-it's as simple and complex as that" (p. 129). Optimizing pedagogical reform goes through recognizing the importance of "the human face" of school reform which takes into account the feelings, wants, and insights of both teachers and leaders along with their values and/or pedagogical assumptions (Shahan, 1976). Reforming schools involve the alteration of beliefs and assumptions about instructional strategies. Change materializes only when the stakeholders within the school seriously probe their beliefs and transform their instructional practices. Altering classroom practices necessitates probing pedagogical beliefs, values and norms. In other words classrooms are in need of "reculturing"-reshaping of values, beliefs and mindsets (Hargreaves, 1997). The alteration of classroom pedagogical practices entails "fixing people" (Fullan, 1982). Given the centrality of the teachers' role, there is a need to document how teachers conceptualize pedagogy and pedagogical practices when they are charged with implementing a curriculum innovation. As agents of change, therefore, teachers' mental framework needs to be analyzed to identify challenges and pursue avenues for reform.

Teacher thinking research needs to be encouraged to capitalize on information accumulated to formulate reform policies that are feasible and appropriately engineered for teachers to appropriate reform ideals. Freiman-Nemser and Floden highlight the centrality of teacher thinking research in the sense that it "can shape policy; inform predictions about how teachers will respond to policy, and to provide hints for shaping those responses" (1986, p. 505). Knowledge of teacher 
thinking can disclose the tacit or implicit frameworks that underlie teacher beliefs and actions in classroom, in addition to their conscious and rational or explicit construction of classroom events. The assumption that teachers are receptive to objective scientific knowledge about pedagogy and directly apply it to their teaching has been negated in this research because teacher thinking or mental life cannot exist independent of the sociocultural environment that frames and constructs it. Therefore, a cultural analysis of teacher thinking can illuminate the way in which culture as a set of constitutive rules construct teacher thinking and teaching. Otherwise, efforts at reform will remain on the surface and will not lead to change in teacher's nature and deep-seated notions about pedagogy and instructional practice.

There is a compelling need to further document teachers' cultural models on teaching and learning so as to construct a corpus of research findings that would advantageously inform educational policy. Understanding the cultural foundation of teaching and learning could assist in the design of in-service workshops and teacher training modules that target specific and critical areas in teachers' conceptualization of pedagogy and pedagogical practices. By aiding teachers question their own teaching, they would be in a better position to problematize the taken-for-granted aspect of their work and visualize alternative courses of action that challenge and supplant some their cherished beliefs and practices. Saavedra (1993) puts forth that " through understanding their world and themselves with their world, teachers engage in the process of creating and shifting knowledge, meanings, ideologies and practices and thus transform themselves and conditions of their lives" (p. 272). Thus, teachers could be made aware of reform conducive and reform resistant dimensions of the cultural meaning system they embrace. Along with the focus on how culture constructs pedagogy, questions could also focus on how social, political, and economic contexts construct education.

\section{References}

Alexander, R. J. (2001). Culture and pedagogy: International comparisons in primary education. Oxford: Blackwell.

Alexander, R. J. (2009). Towards a comparative pedagogy in R. Cowen \& A. M. Kazamias, (Eds.), International handbook of comparative education (pp. 923-942), London: Springer.

Chafi, M.E., Elkhouzai, E. \& Ouchouid, J. (2016). Teacher excessive pedagogical authority in Moroccan primary classroom. American Journal of Educational Research, 4(1), 134-146.

Clarke, M. A. (1994). The dysfunctions of the theory/practice discourse. TESOL Quarterly, 28(1), 9-26.

Clarke, P. (2003). Culture and classroom reform: The case of the district primary education project, India. Comparative Education, 39 (1), 27-44.

Day, C., Calderhead, J. \& Denicolo, P. (Eds.), (1993). Research on teacher thinking: Understanding professional development. New York: Falmer Press.

D'Andrade, R. G. (1995). The development of cognitive anthropology. Cambridge New York: Cambridge University Press.

D’Andrade, R. G. (2005). Some methods for studying cultural cognitive structures. In N. Quinn (Ed.), Finding culture in talk: A collection of methods (pp. 83-104). New York: Palgrave Macmillan.

Erickson, F. (2002). Culture and human development. Human Development, 45(4), 299-305.

Elliot, J. (1994).The teacher's role in curriculum development: an unresolved issue in English attempts at curriculum reform', Curriculum Studies: A Journal of Educational Discussion and Debate, 2 (1), 43-69.

Feiman-Nemser, S., \& Floden, R. (1986). The cultures of teaching. In M. Wittrock (Ed.), Handbook of Research on Teaching, (3rd ed., pp. 506-26). New York: Macmillan.

Fullan, M. (1982). The meaning of educational change. New York: Teachers College Press.

Fullan, M. D. (1997). The complexity of the change process. In M. Fullan (Ed.), The challenge of school change (pp. 34-56). Arlington Heights, Illinois: IRI/Skylight Training and Publishing.

Fullan, M. (2007). The new meaning of educational change (4th ed.). New York: Teachers College Press.

Fuller, B., \& Clarke, P. (1994). Raising school effects while ignoring culture? Local conditions and the influence of classroom tools, rules, and pedagogy. Review of educational research, 64(1), 119-157.

Goodson, I. (2003). Professional knowledge, professional lives: studies in education and change. Maidenhead \& Philadelphia: Open University Press.

Healey, F. H., \& De Stefano, J. (1997). Education reform support: A framework for scaling up school reform. Policy Paper Series (Research Triangle Park, NC: Research Triangle Institute). Retrieved from files.eric.ed.gov/fulltext/ED411578.pdf(26/05/2015).

Guthrie, G. (2011). The progressive education fallacy in developing countries: In favour of formalism. New York: Springer.

Hargreaves, A. (1997). Introduction. In A. Hargreaves (Ed.), Rethinking educational change with heart and mind: 1997 ASCD yearbook (pp. viii-xv). Alexandria, Virginia: Association for Supervision and Curriculum Development.

Harris, A. (2002). School improvement: What's in it for schools? London: Routledge Fahner. 
Holland, D. \& Quinn, N. (1987). Culture and cognition. In N. Quinn \& D. Holland (Eds.), Cultural models in language and thought (pp. 3-42). New York: Cambridge University Press.

Gay, G. (2010). Culturally responsive teaching: Theory, research, and practice (2nd ed.). New York, NY: Teachers College Press.

Gee, J. P. (1999). An introduction to discourse analysis: Theory and method. New York: Routledge.

Gee, J. P. (2004). Discourse analysis: What makes it critical? In Rebecca Rogers (Ed.), An introduction to critical discourse analysis (pp. 19-50). New Jersey: LEA.

Gee, J. P. (2014). How to do discourse analysis: A toolkit. (2nd ed.). New York, NY: Routledge.

Goh, C. (1999). Nationwide curriculum innovation: How do we manage? In P. Goh, P. Doyle \& C. Kennedy (Eds.), Exploring change in English language teaching (pp. 5-18).Oxford: Macmillan.

Keesing, R. (1987). Models, folk and cultural: Paradigms regained? In D. Holland, \& N. Quinn (Eds.), Cultural Models in Language and Thought (pp. 369-393). Cambridge: Cambridge University Press.

Keys, P. (2007). A knowledge filter model for observing and facilitating change in teachers' beliefs. Journal of Educational Change, 8(1), 41-60.

Markee, N. (1997). Managing curricular innovation. Cambridge: Cambridge University Press.

Ministry of National Education and Vocational Training. (1999). Palmi:ta:q lwatani: littarbijja Wattakwi:n [National Charter for Education and Training]. Retrieved from http://www.men.gov.ma/Ar/Pages/charteEF.aspx

Ministry of National Education, Higher Education, Staff Training and Scientifc Research. (2009). Paddali:1 lbidaru:zi: littaSli:m lPibtida?i: (2nd ed.) [Primary school pedagogical guide]. Bab Rouah, Morocco: Author.

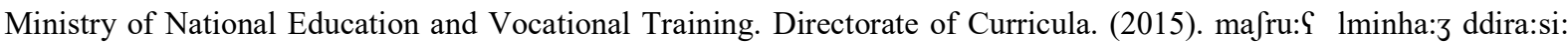
lmonaqqah lissanawa:t 1ParbaS 1Pu:wla: littaSli:m 1Pibtida:i: [The Project of the Revised Curriculum for the First Four Years of Primary Education]. Retrieved from www.men.gov.ma/.../curriculum-primaire-revise 6jui...

O'Donnell, B. (2001). Professional recognition and the quality of teaching and learning in schools. In K. Kennedy (Ed.), Beyond the rhetoric: Building a teaching profession to support quality teaching. College year book 2001 (pp. 8595). Deakin West, ACT: Australian College of Education.

Pajares, M. F. (1992). Teachers' beliefs and educational research: Cleaning up a messy construct. Review of Educational Research, 62(3), 307-332.

Pollard, A. (1985). The social world of the primary school. London: Holt, Rinehart and Winston.

Preston, B. (1996). Award restructuring: A catalyst in the evolution of teacher professionalism. In T. Seddon (Ed.), Pay, professionalism and politics: Reforming teachers, reforming education (pp. 156-92). Melbourne: Australian Council for Educational Research.

Quinn, N. (2005a). Introduction. In N. Quinn (Ed.), Finding culture in talk: A collection of methods (pp. 1-34). New York, NY: Palgrave Macmillan.

Sarason, S. (1996). Revisiting "the culture of the school and the problem of change." New York: Teachers College Press.

Schlechty, P. (1997). Inventing better schools: An action plan for educational reform. San Francisco,CA: Jossey-Bass.

Shahan, Keith E. (1976). The administrator's role in developing nnovations. Unpublished manuscript, Harvard Graduate School of Education.

Shore, B. (1996). Culture in mind: Cognition, culture, and the problem of meaning. Oxford: Oxford University Press.

Shweder, R. (1990). Cultural psychology-What is it? In J. W. Stigler, R. A. Shweder, \& G. Herdt (Eds.), Cultural psychology: Essays on comparative human development (pp. 1-46).New York: Cambridge University Press.

Stacey, R. (1996). Complexity and creativity in organizations. San Francisco: Berrett-Koehler.

Strauss, C. \& Quinn, N. (1997). A cognitive theory of cultural meaning. New York: Cambridge University Press. 